\title{
Simple, robust eddy correlation amplifier for aquatic dissolved oxygen and hydrogen sulfide flux measurements
}

Daniel F. McGinnis ${ }^{1,2^{*}}$, Sergiy Cherednichenko ${ }^{1}$, Stefan Sommer ${ }^{1}$, Peter Berg ${ }^{3}$, Lorenzo Rovelli ${ }^{1}$, Ralf Schwarz ${ }^{1}$, Ronnie N. Glud $2,4,5$, and Peter Linke

${ }^{1}$ IFM-GEOMAR, Leibniz Institute of Marine Sciences, RD2 Marine Biogeochemistry, Kiel, Germany D-24148

${ }^{2}$ Southern Danish University, Institute of Biology and Nordic Center for Earth Evolution (NordCee), 5230 Odense M, Denmark ${ }^{3}$ Department of Environmental Sciences, University of Virginia, Charlottesville, VA 22904-4123

${ }^{4}$ Greenland Climate Research Centre (Co. Greenland Institute of Natural Resources), Kivioq 2, Box 570, 3900 Nuuk, Greenland ${ }^{5}$ Scottish Association for Marine Science, Dunstaffnage Marine Laboratory, PA37 1QA, Dunbeg, Scotland

Web Appendix A

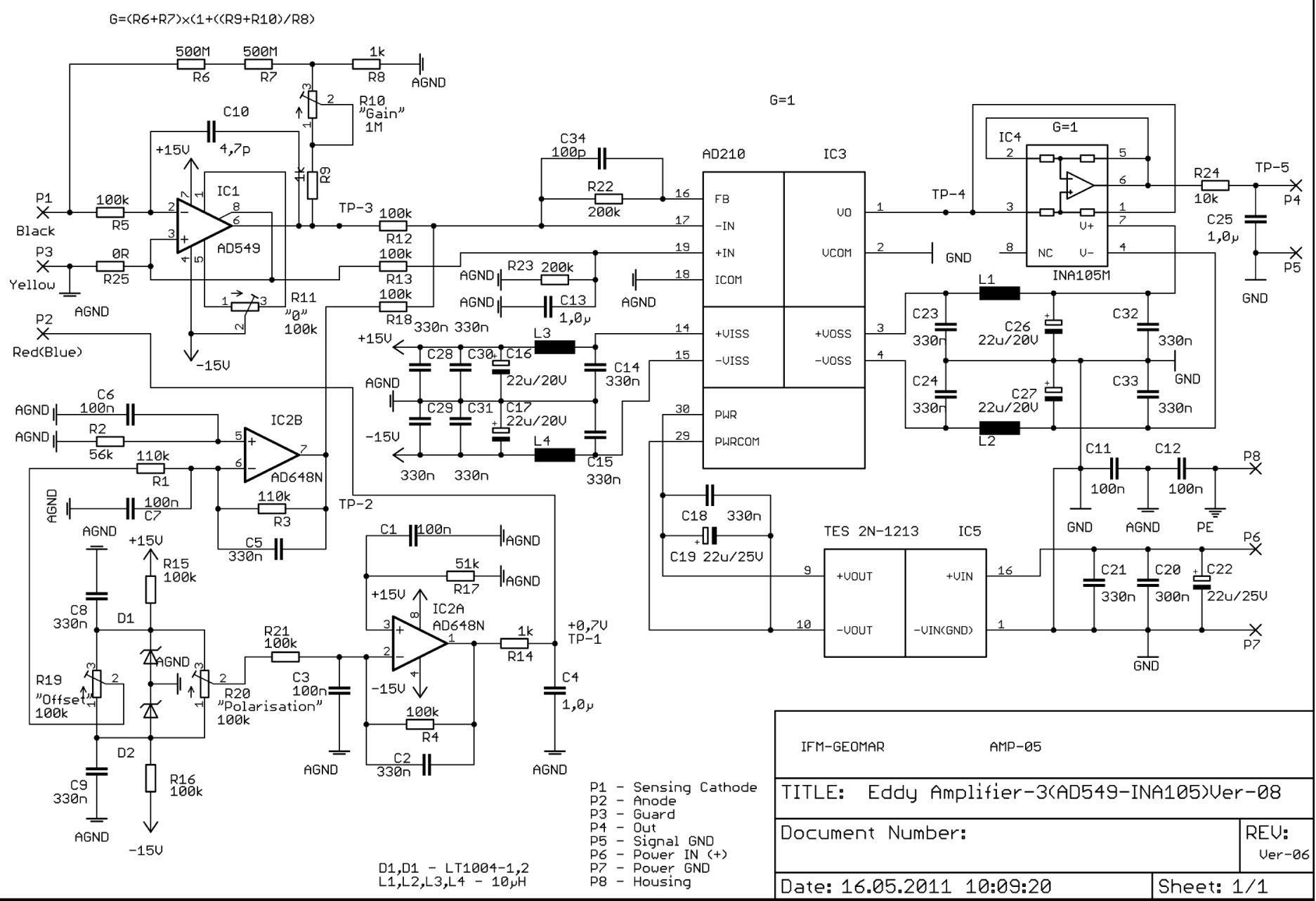

